\section{Mentoring matters}

\section{Mentoring enhances the experience of mentees; how- ever, mentors and their institutions will also reap the rewards of a mentorship culture.}

Scientific research involves teams composed of graduate students, postdoctoral fellows, technicians and undergraduate students working on various defined aspects of a larger question. Mentoring, defined here as activities undertaken to train or advise the mentee (the recipient of such counsel) so that they can work more effectively and progress, is an important activity in this context. Clearly, sound mentorship can contribute significantly to the intellectual and professional development of mentees. But mentors also stand to gain strong leadership skills in this process, and the ability to draw the best from a team can only aid in the overall success of one's research agenda. While picking the appropriate problem and the right approaches is fundamental to a running a successful research programme, capable mentoring of laboratory members is also crucial. It is also to the advantage of research institutions to foster a culture of mentoring not only for trainees, but also for new faculty members who would benefit from the guidance of their senior colleagues.

Appreciating the importance of good mentorship, understanding what it means to be a good mentor and then implementing these principles may come naturally to some, but it is by no means a universal skill or one that is acquired during conventional research training. Exposure to some fundamental mentorship skills should be encouraged for all principal investigators (PIs). At many universities, mentorship training is now frequently offered within broader workshops on leadership and laboratory management that bring senior and mid-level faculty members together with new PIs. Research organizations such as the Howard Hughes Medical Institute in the US and EMBO in Europe provide training courses in laboratory management that also cover mentorship. Extensive resources for developing mentoring skills are also available online, for example, through the National Postdoctoral Association, the Howard Hughes Medical Institute and the American Association for the Advancement of Science. Similarly, annual society meetings often include mentoring workshops. For many newly minted PIs, recruiting, training and retaining the strongest candidates to their laboratory can be a source of considerable anxiety. Confidence in their mentorship abilities may help alleviate these concerns to some extent.

What are some of the objectives of good mentoring? A good starting point is to understand that the goal is not to turn out clones of one's self but rather to be able to recognize the individual potential of mentees and to encourage them in research projects that match their interests, skills and personalities. Successful mentors foster creativity and independence and ensure that trainees have opportunities to develop essential skills beyond bench work for their future success in research, for example, in critical analysis and communication.
Instilling high ethical standards in one's trainees is also important. Finally, for mentees with family commitments, a mentor who can provide an experienced perspective on the challenges of balancing work and family is invaluable.

New faculty members could also benefit greatly from being mentored by their senior colleagues. New PIs face multiple challenges - setting up a laboratory from scratch, recruiting and managing a team, completing administrative tasks, managing a budget, setting research priorities, writing and reviewing grants and papers, and designing and teaching classes - and often these responsibilities have to be juggled with family commitments. Time management is therefore an essential skill for the new PI to master. Experienced faculty members can help guide new colleagues through this thicket of responsibilities, many of which most new PIs would not have had any exposure to previously. Seasoned faculty members could also advise new PIs on developing a viable research agenda, navigating an increasingly competitive funding environment, negotiating with administrators and managing complex situations with personnel. Sometimes, the goals of mentors and mentees do not coincide, making a training process difficult for both parties. Involving external mentors, for example, as is done on thesis advisory committees for graduate students, should be encouraged.

Although a strong track record in mentorship is unlikely to be a decisive factor in tenure or funding decisions unless bolstered by a strong publication record, its importance in research is becoming better appreciated. Many universities and societies now have annual awards for excellence in mentorship. The annual Women in Cell Biology Career Recognition Senior Awards presented at the American Society for Cell Biology meeting acknowledges a commitment to mentorship over a long career in science. In 2005, Nature launched the annual Nature Awards for Mentoring in Science to recognize both outstanding lifetime and mid-career achievements in scientific mentoring (http://www.nature.com/ nature/awards/mentorship/index.html). The American Association for the Advancement of Science also has annual Mentor Awards to honour the contributions of individuals who have mentored significant numbers of trainees from underrepresented groups in science and engineering. Funding agencies are now beginning to place greater emphasis on mentoring. For example, the National Science Foundation and some National Institutes of Health awards ask grantees to include detailed plans for mentoring postdoctoral trainees in grant applications.

Alas, researchers with enviable publication records are not always committed to good mentoring. Graduate students and postdoctoral trainees would be well advised to consider the importance of thoughtful mentoring when choosing an advisor. Mentees exposed to good mentoring are better positioned to absorb these attributes and become successful mentors themselves. Universities, research organizations and funding bodies must promote a culture of mentorship through all levels of academia as a supportive training environment will define and develop the next generation of scientists. 